\title{
Validation of a HPLC Method for the Determination of 4-Hydroxy-3-methoxycinnamyl Alcohol in Extracts Obtained from Stachyurus Chinensis Franeh
}

\author{
Ji Jing ${ }^{1,2}$, Cao Jie ${ }^{2} \&$ Cheng Jianming ${ }^{2}$ \\ ${ }^{1}$ College of Pharmacology, Nanjing University of Chinese Medicine, Nanjing 210023, China \\ ${ }^{2}$ Jiangsu Collaborative Innovation Center of Chinese Medicinal Resources Industrialization, Nanjing 210023, \\ China \\ Correspondence: Cheng Jianming, College of Pharmacology, Nanjing University of Chinese Medicine, \\ 138Xianlin Road, Nanjing, RP China. Tel: 86-135-8520-6999. E-mail: cjm7895@163.com
}

Received: August 23, 2019

Accepted: September 2, 2020

Online Published: September 30, 2020

doi:10.5539/ijb.v12n3p40

URL: doi: 10.5539/ijb.v12n3p40

\begin{abstract}
Stachyuri medulla helwingiae medulla is a wild used genus in clinic, especially in promoting lactation. Most study confirmed it's evidently rich in polysaccharide. In this study, a HPLC method for the quantification of Coniferyl alcohol (4-Hydroxy-3-methoxycinnamyl alcohol) was validated. The results showed that the HPLC method was linear $(0.01-0.16 \mathrm{mg} / \mathrm{ml})$ with good accuracy, precision and robustness. The content of Coniferyl alcohol in different formula granule ranged from $0.091-0.163 \mathrm{mg} / \mathrm{g}$. Thus, the method might be used for the standardization of the extracts based on the Coniferyl alcohol marker.
\end{abstract}

Keywords: HPLC; Coniferyl alcohol; Stachyurus Chinensis Franeh; quantification

\section{Introduction}

Xiaotongcao, a traditional Chinese medicine, has three sources: Stachyurus himalaicus Hook. F. et Thorns., Stachyurus chinensis Franeh and Helwingia japonica (Thunb.) Dietr. Dietr-dried stem pith ("Chinese Pharmacopoeia", 2015). Cut stem in autumn, cut into segments, take out pith while fresh, straighten and dry. It has the functions of clearing heat, diuresis and lower milk. At present, there are few studies on the chemical constituents of the herb, and there is no content determination item in the Chinese Pharmacopoeia 2015 edition. It has been reported that the content of polysaccharides in is relatively high. In order to develop and utilize Herba Stachyurus, the water-soluble components were systematically studied for the first time in order to lay a foundation for further study on the chemical compositions and pharmacological activity of its formula granules. At present, the main market circulation is Stachyurus chinensis Franeh, which is the main research object in this study. Moreover, we have identified glycyrrhizic acid, Hydroxy-3-methoxycinnamaldehyd and vanillin by HPLC-MS. Though the content of those all lower than $0.01 \%$, no further study in content determination.

Table 1. Different samples of different Stachyurus Chinensis Franeh

\begin{tabular}{llll}
\hline No. & Sample of Category & Lot Number & Place of Production \\
\hline 1 & & YC1809096 & Xinying Town, Lixian County, Liangshan Yi Autonomous Prefecture, Sichuan Province \\
2 & Medicinal materials & YC1801020 & Nanping village, Lichuan, Enshi Tujia and Miao autonomous prefecture, Hubei province \\
3 & & YC1801028 & Sha Dao Gou Zhen, Xuanen County, Enshi Tujia Miao Autonomous Prefecture, Hubei Province \\
4 & Freeze-dried & DG1801020 & Tianjiang Pharmaceutical Co., Ltd. \\
5 & powder & 1609071 & \\
6 & & 1703048 & \\
7 & Formula granule & 17111451 & Tianjiang Pharmaceutical Co., Ltd. \\
8 & & 18031231 & \\
9 & & 18011091 & \\
\hline
\end{tabular}


<smiles>COc1cc(/C=C/CO)ccc1O</smiles>

Figure 1. Chemical structure of Coniferyl alcohol

\section{Materials and Methods}

Stachyuri chinensis Franch provided by Tianjiang Pharmaceutical Co., Ltd. (Table 1). The plants were authenticated by professor Xunhong Liu (Nanjing University of Chinese medicine). Acetonitrile (HPLC grade) and formic acid (HPLC grade) were purchased from Merck (Darmstadt, Germany). Deionized water (18.2M 2 ) was produced by Milli-Q system (Millipore, Bedford, MA, USA). All solvent were filtered through $0.45 \mu \mathrm{m}$ membrane and degassed under reduced pressure and ultrasonic bath. 4-Hydroxy-3-methoxycinnamyl alcohol (Lot\# H1801149, $100 \mathrm{mg}$ ) was purchased from Aladdin Industrial Corporation \#1008 Qigang Rd. Fengxian, Shanghai. All the other reagents and solvent used were of analytical grade.

\section{Chromatographic System}

The HPLC analysis was performed using an Empower system (Waters, USA) coupled to a 1252 binary HPLC pump, 2998 dual absorbance detector and 2707 auto sampler. To obtain optimal chromatographic conditions with a good separation of as many peaks possible, different HPLC parameters including column types, mobile phase composition, gradient elution profile, flow rate of the mobile phase and column temperature were examined and compared. Thus, various column: Aglient TC-C18 $(150 \mathrm{~mm} * 4.6 \mathrm{~mm}, 5 \mu \mathrm{m})$; Thermol $(150 \mathrm{~mm} * 4.6 \mathrm{~mm}, 5 \mu \mathrm{m})$; Kromasil $(150 \mathrm{~mm} * 4.6 \mathrm{~mm}, 5 \mu \mathrm{m})$, mobile phase (acetonitrile-water and methanol-water with different modifiers, including formic acid, acetic acid and phosphoric acid), column temperatures $\left(25^{\circ} \mathrm{C}\right.$, $\left.35^{\circ} \mathrm{C}, 40^{\circ} \mathrm{C}\right)$, and mobile phase flow rates $(0.5,0.8$ and $1.0 \mathrm{~mL} / \mathrm{min})$ were evaluated, respectively. As a consequence, optimized HPLC conditions were developed as follows by comprehensively comparing the resolution, baseline, elution time and numbers of characteristic peaks. An Agilent TC- $\mathrm{C}_{18}(150 \times 4.6 \mathrm{~mm}, 5 \mu \mathrm{m})$ reverse-phase silica gel column was used for chromatographic separation. Several solvent systems were employed; solvents that constituted the mobile phase were acetonitrile (A) and $0.1 \%$ formic acid (B) in Tab1. Finally, reconditioning steps of the column was not monitor. $\mathrm{CH}_{3} \mathrm{OH} / \mathrm{H}_{2} \mathrm{O}(10: 90, \mathrm{v} / \mathrm{v})$ were used as solutions for cleaning the injection needle. The result of flow rate was $1.0 \mathrm{~mL} / \mathrm{min}$ and the injection volume were $10 \mathrm{uL}$. The column temperature was maintained at $35^{\circ} \mathrm{C}$. HPLC fingerprints of Stachyurus chinensis Franeh were studied, while the UV wavelength was $254 \mathrm{~nm}$ from HPLC-DAD-3D spectrum of Stachyurus chinensis Franeh.

Table 2. Flow rates of mobile phase

\begin{tabular}{lll}
\hline Time & Acetonitrile (A) & $0.1 \%$ formic acid (B) \\
\hline 0 & 5 & 95 \\
5 & 5 & 95 \\
20 & 20 & 80 \\
25 & 28 & 72 \\
45 & 53 & 47 \\
55 & 5 & 95 \\
\hline
\end{tabular}



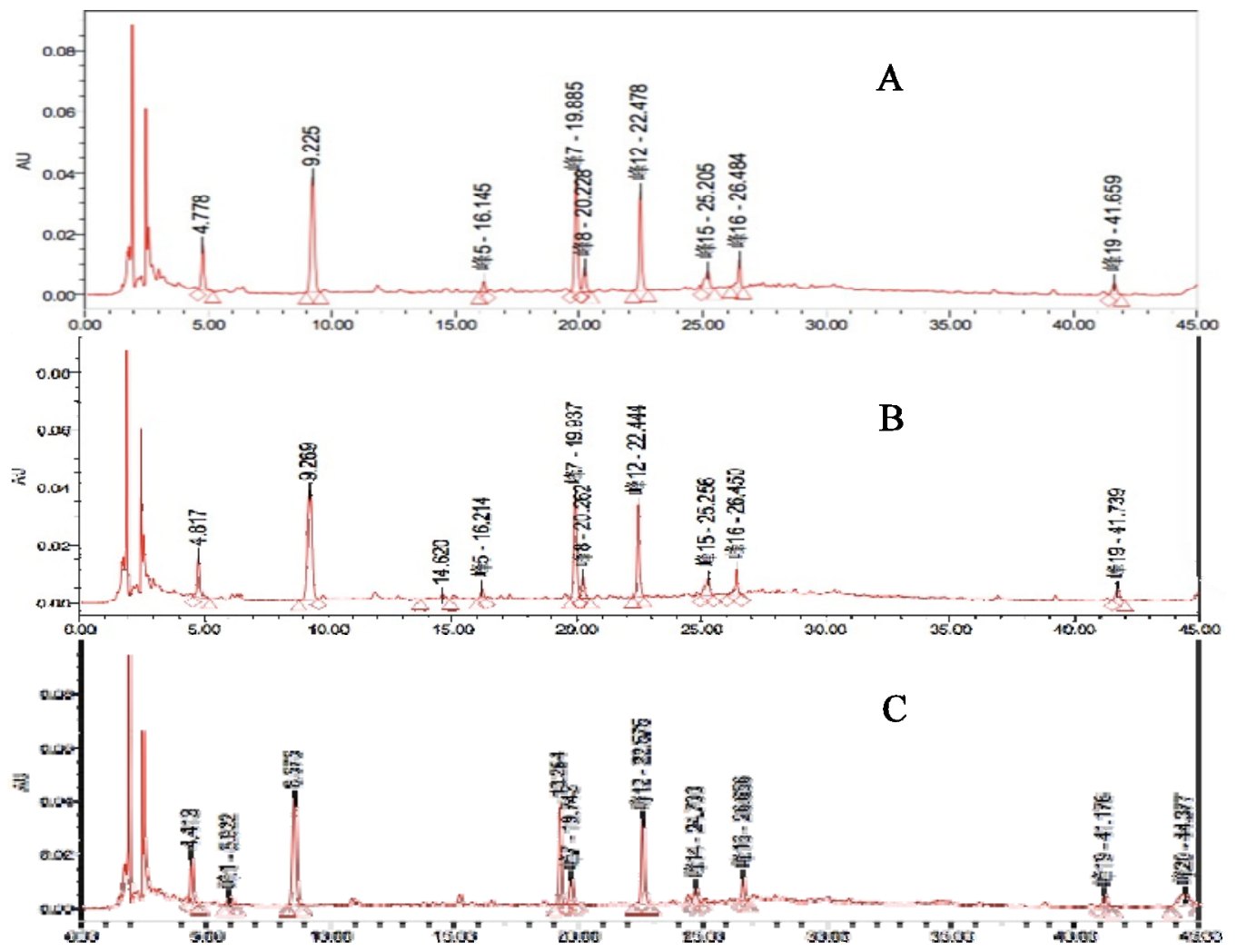

Figure 2. Effect of different column temperatures, A: column temperature $25^{\circ} \mathrm{C}$; B: column temperature $30^{\circ} \mathrm{C}$; C: column temperature $35^{\circ} \mathrm{C}$
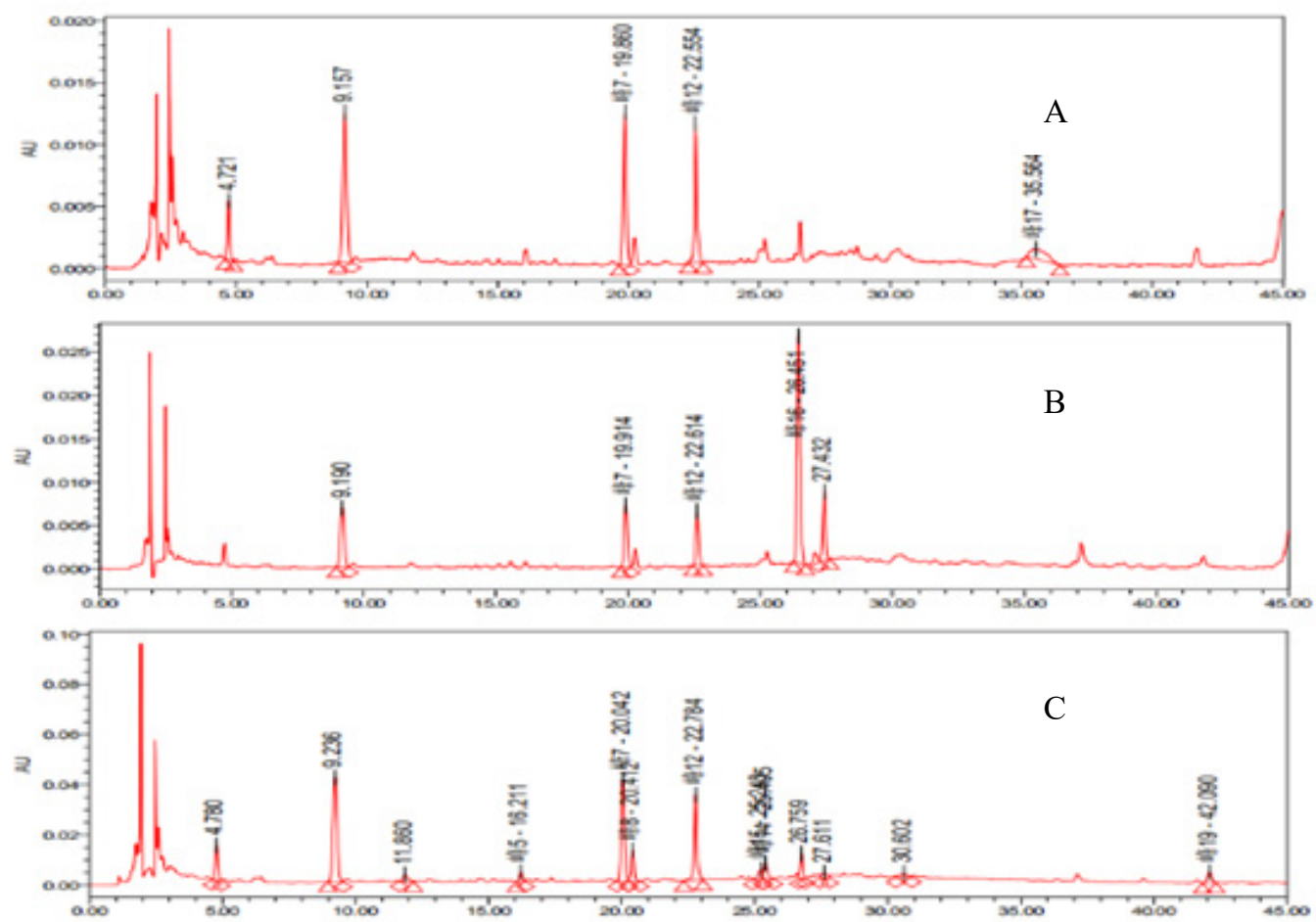

Figure 3. Effect of different flow rate, A: $1.0 \mathrm{~mL} / \mathrm{min} ; \mathrm{B}: 0.8 \mathrm{~mL} / \mathrm{min} ; \mathrm{C}: 0.5 \mathrm{~mL} / \mathrm{min}$. 


\section{Optimization of sample preparation}

The sample pretreatment procedure is often the most important step, which can greatly influence the repeatability and accuracy of the entire analysis. Compared with refluxing and heating, ultrasonic extraction was simpler and more effective. Subsequently other experimental factors were optimized as follow: different extraction-solvent ratios $\mathrm{CH}_{3} \mathrm{OH} / \mathrm{H}_{2} \mathrm{O}(0: 100,30: 70,50: 50,70: 30$, v/v), different extraction time (40, 60 and 80 $\mathrm{min})$, and different solvent volume $(3,10,20 \mathrm{ml})$. Comparing the number, areas and resolution of the chromatographic peaks obtained by the different extraction procedures, the optimized extraction conditions were determined as ultrasonic with $10 \mathrm{ml} \mathrm{CH} \mathrm{CH}_{3} \mathrm{OH} \mathrm{H}_{2} \mathrm{O}(30: 70, \mathrm{v} / \mathrm{v})$ for $40 \mathrm{~min}$ and then centrifuged at $12000 \mathrm{rpm}$ for 5 min. The supernatant was filtered through $0.45 \mu \mathrm{m}$ cellulose regenerated membrane before analysis.
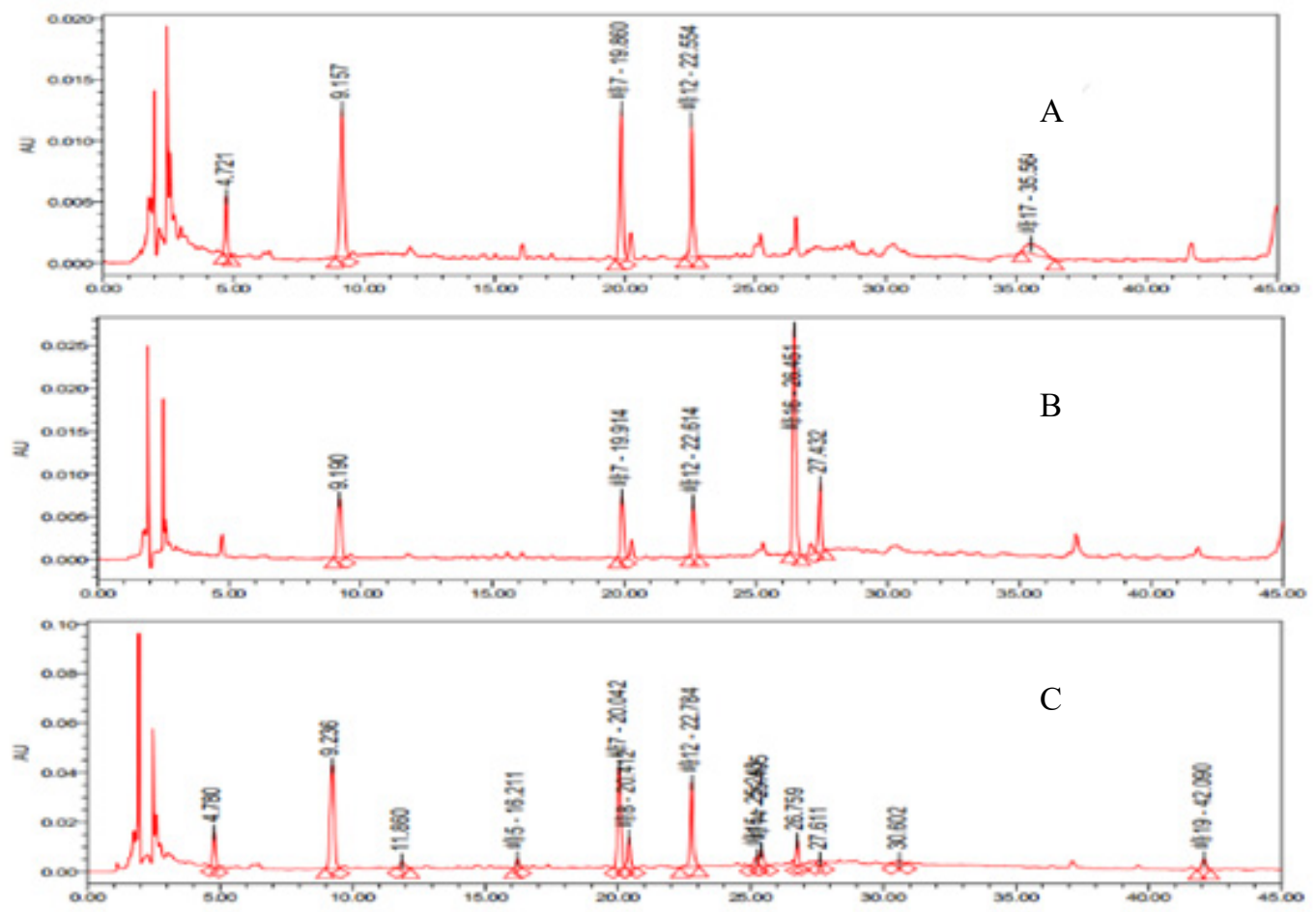

Figure 4. HPLC chromatograms of different extraction methods, A: Ultrasonic extraction; B: reflux extraction; C: Boiling water extraction 


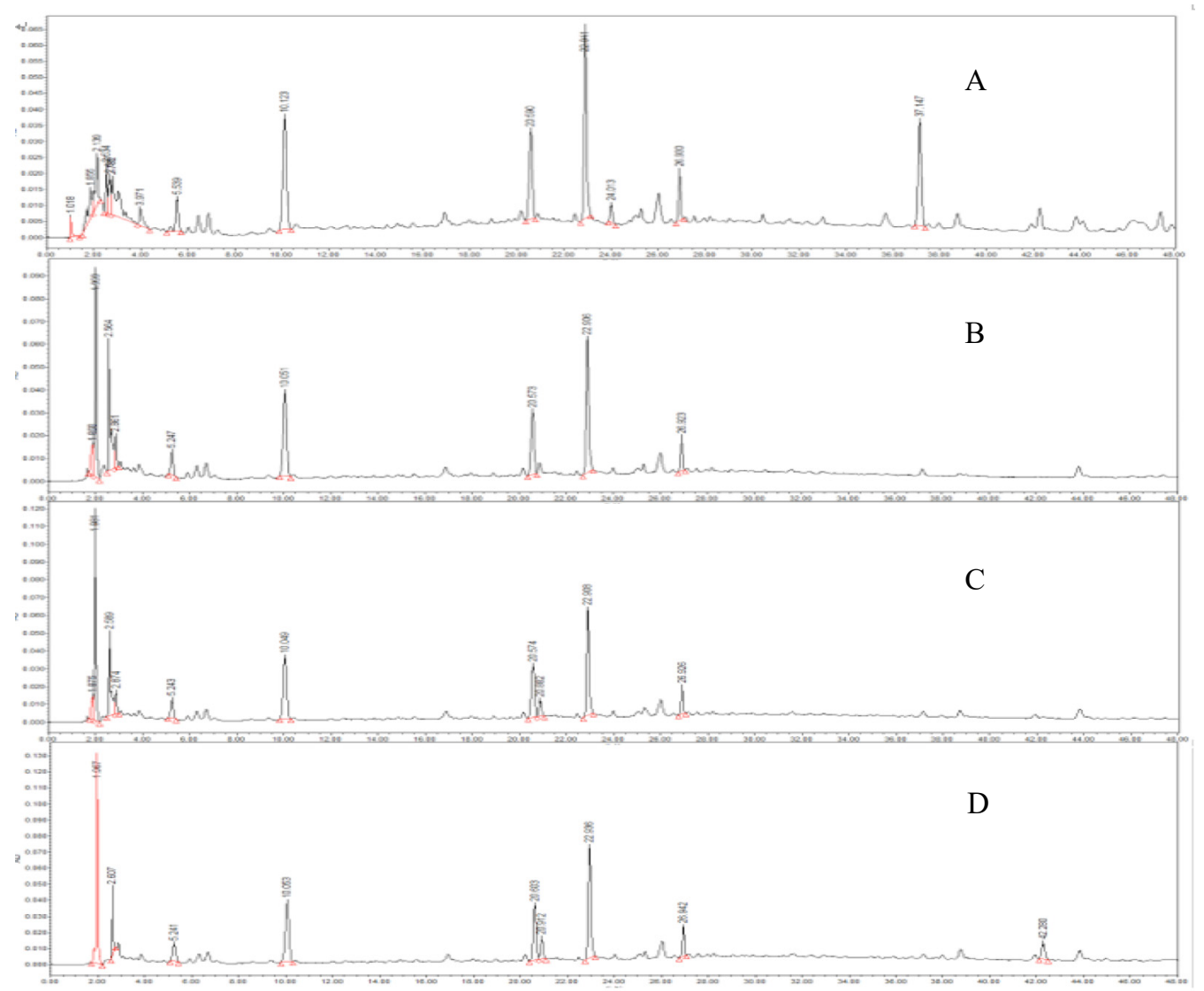

Figure 5. Effect of different extraction solvents, A: Water; B: methanol:water (3:7,v/v); C: methanol:water $(5: 5, \mathrm{v} / \mathrm{v}) ; \mathrm{D}:$ methanol:water $(7: 3, \mathrm{v} / \mathrm{v})$

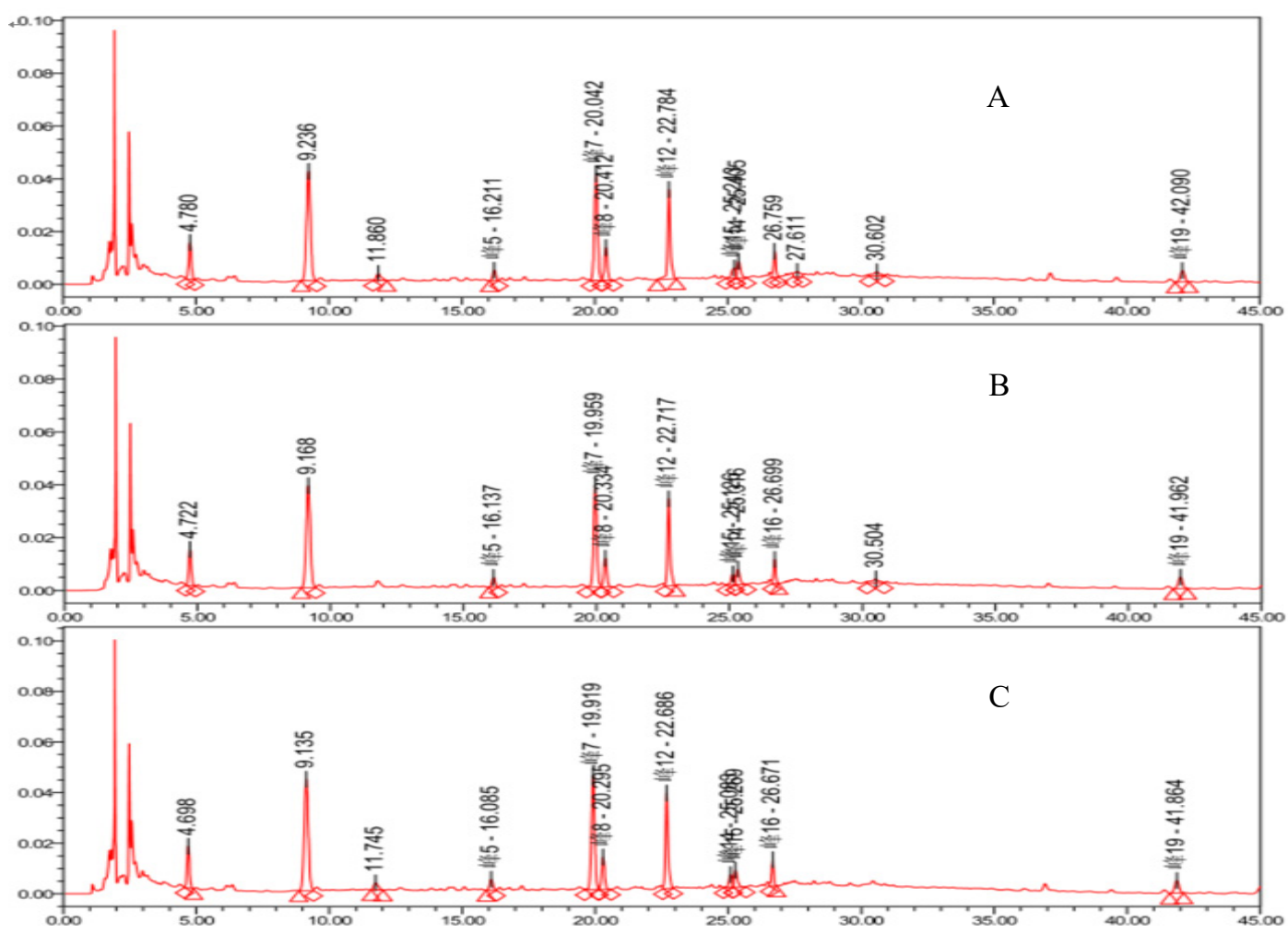

Figure 6. HPLC chromatograms of different extraction time, A: $40 \mathrm{~min}$; B: $60 \mathrm{~min}$; C: $80 \mathrm{~min}$ 

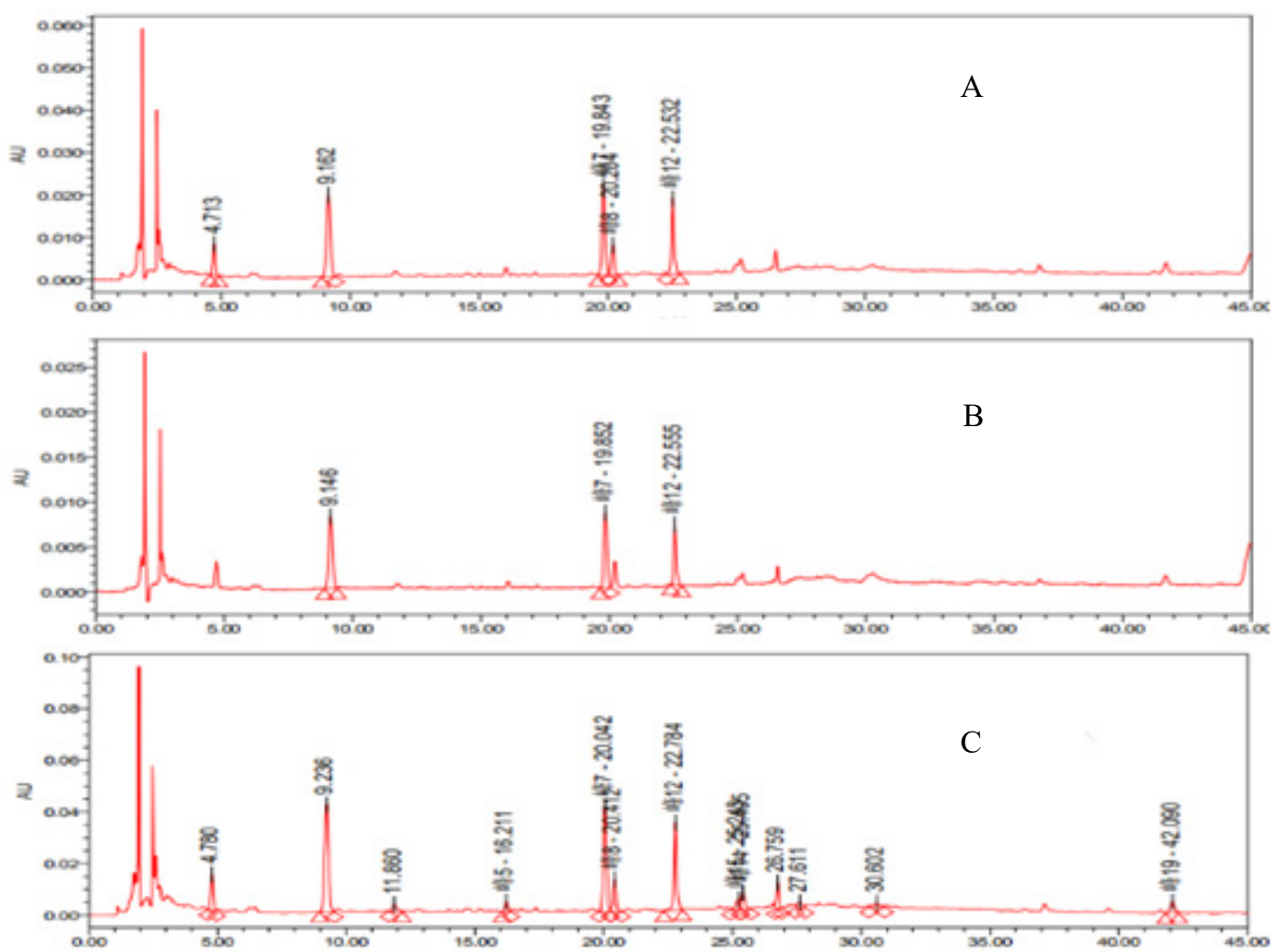

Figure 7. HPLC chromatograms of different solvent volume (A: 10mL; B: 20mL; C: 30mL)

\section{Method Validation}

\subsection{Calibration Curves}

Coniferyl alcohol standards $(1.6 \mathrm{mg})$ were diluted with $\mathrm{CH}_{3} \mathrm{OH} / \mathrm{H}_{2} \mathrm{O}(30: 70$, v/v) (HPLC grade) by sonication for $5 \mathrm{~min}$, fixed in $10-\mathrm{mL}$ brown flasks, and confected to $0.16 \mathrm{mg} / \mathrm{mL}$ stock solution. The stock solution was diluted to different concentrations-0.01, 0.02, 0.04, $0.08 \mathrm{~g} / \mathrm{L}$ for the HPLC analysis. The probability of exposure of samples to strong light was minimized as much as possible. Calibration curves of Coniferyl alcohol was obtained by plotting the peak area versus the concentration. The regression equation and the correlation coefficient were calculated.

\subsection{Precision, Repeatability, Accuracy and Stability}

The same sample was analyzed six times under the chromatographic conditions, and then the RSD of the standard solution was calculated based on the content of Coniferyl alcohol. For the repeatability, six different samples $(0.5 \mathrm{~g}$ per sample $)$ from the same Lot number were accurately weighed and extracted under the same preparation conditions. After extraction, the content of Coniferyl alcohol in each sample was determined under the chromatographic conditions and the RSD value was calculated. Stability was obtained by analysis the same sample into the system at $0,2,4,8,12$ and $24 \mathrm{~h}$ after preparation of the sample. The relative standard deviation (RSD) of each sample at $24 \mathrm{~h}$ was determined.

\subsection{Evaluation of Sample Recovery}

Six samples with known content of detected substances were accurately weighed and a certain amount of mixed standard was added to each sample. The amount added was the same that of the original sample, and then the recovery rate was analyzed.

\section{Results and discussion}

\subsection{Optimization of HPLC Parameters}

Formula granule was extracted from water, which easily separate in high ratio of aqueous mobile phase. Acetonitrile (A) and $0.1 \%$ formic acid (B) were selected as mobile phase. Column temperature variations influence on the resolution and the peak shape were considered. Different temperatures of $25,30,35,40^{\circ} \mathrm{C}$ were 
tested and the results demonstrated that resolution, peak shape and retention all affected. There are partial superimposed peaks in chromatograph of $40^{\circ} \mathrm{C}$. So as the flow rate of 0.5 and $0.8 \mathrm{~mL} / \mathrm{min}$. Ultimately, a temperature of $35^{\circ} \mathrm{C}$ and the flow rate of $1.0 \mathrm{~mL} / \mathrm{min}$ were deemed optimal. Chromatograph of different conditions show in Fig 2-7.

\subsection{Validation of the Method}

The linearity, regression and linear rages of Coniferyl alcohol determined using the developed HPLC method. The developed method had good stability ( $\mathrm{RSD}<3 \%$ ), precision $(\mathrm{RSD}<2 \%$ ), repetitiveness $(\mathrm{RSD}<2 \%)$ and recovery (96.54-102.85\%). Results show in Tab 2-5.

Table 3. Standard curve of Coniferyl alcohol

\begin{tabular}{cccc}
\hline Standards & $\begin{array}{c}\text { Regression equation } \\
(\mathrm{mg} / \mathrm{ml})\end{array}$ & Correlation coefficient & $\begin{array}{c}\text { Linear range } \\
(\mathrm{mg} / \mathrm{ml})\end{array}$ \\
\hline 1 & $\mathrm{y}=2 \mathrm{E}+07 \mathrm{x}-66339$ & $\mathrm{R}^{2}=0.9993$ & $0.01-0.16$ \\
\hline
\end{tabular}

Table 4. Results of stability experiments

\begin{tabular}{ccc}
\hline \multirow{2}{*}{ Analyte (time) } & \multicolumn{2}{c}{ Stability } \\
\cline { 2 - 3 } & Peak area & RSD (\%) \\
\hline 0 & 272747 & \\
2 & 267501 & $2.48 \%$ \\
4 & 264019 & \\
8 & 265937 & \\
12 & 262667 & \\
24 & 254750 & \\
\hline
\end{tabular}

Table 5. Results of precision \& repetitive experiments

\begin{tabular}{lllll}
\hline \multirow{2}{*}{ Analyte } & Precision & & Repetitiveness & \\
\cline { 2 - 5 } & Peak area & RSD $(\%)$ & Content $(\mathrm{mg} / \mathrm{g})$ & $1.64 \%$ \\
\hline 1 & 272747 & $1.16 \%$ & $0.0161 \%$ & \\
2 & 266967 & & $0.0160 \%$ & \\
3 & 267501 & & $0.0158 \%$ & \\
4 & 266314 & $0.0163 \%$ & \\
5 & 264019 & & $0.0158 \%$ & \\
6 & 270320 & & $0.0161 \%$ & \\
\hline
\end{tabular}

Table 6. Results of recovery

\begin{tabular}{cccc}
\hline \multirow{2}{*}{ Analyte } & (Added concentration) & (Measured concentration) & \multirow{2}{*}{ Recovery } \\
\hline 1 & $\mu \mathrm{g} / \mathrm{ml}$ & $\mu \mathrm{g} / \mathrm{ml}$ & $97.47 \%$ \\
2 & 16.79 & 16.45 & $98.82 \%$ \\
3 & 16.79 & 16.63 & $102.85 \%$ \\
4 & 16.79 & 17.17 & $96.88 \%$ \\
5 & 16.79 & 16.37 & $97.11 \%$ \\
6 & 16.79 & 16.40 & $96.54 \%$ \\
\hline
\end{tabular}

The calibration curves were constructed by five concentration assays. Regression equation, the correlation coefficients $\left(\mathrm{R}^{2}\right)$ and Linear range listed in Table 2. The high correlation coefficient $\left(\mathrm{R}^{2}>0.999\right)$ showed good linearity correlations.

\section{Application of the validated method in the analysis of the formula granule of Stachyurus Chinensis Franeh}

The validated method was applied for the determination of the formula granule of Stachyurus Chinensis Franeh. The results are shown in Table 6.

Coniferyl alcohol is a part of lignin, through Upton put forward that lignin was chemically related to coniferyl alcohol and later proposed that lignin is a macromolecular substance by ether linkage between coniferyl alcohol units. These precursors include p-coumaryl alcohol, coniferyl alcohol, and sinapyl alcohol (Upton \& Kasko, 
2016). The amorphous network macromolecule formed by C-C and C-O-C bond is the only renewable aromatic material in nature. Ralph et al. (2001) provided that with 2D NMR.

Table 7. Results of content of formula granule

\begin{tabular}{llll}
\hline Lot & Sample weight $(\mathrm{g})$ & Area & Content \\
\hline 1609071 & 0.9791 & 652591 & $0.0163 \%$ \\
1703048 & 0.9458 & 719225 & $0.0180 \%$ \\
17111451 & 0.9608 & 635299 & $0.0159 \%$ \\
18031231 & 0.9358 & 607996 & $0.0162 \%$ \\
18011091 & 0.9733 & 362096 & $0.0091 \%$ \\
\hline
\end{tabular}

Lignin is a kind of natural aromatic polymer widely found in plants, accounting for $15 \%$ to $30 \%$ of the dry weight of plants, and together with cellulose and hemicellulose constitute the skeleton structure of the plant (Ago et al., 2016). It acts as a filler and binder in plant tissue, with the effect of enhancing cell walls and adhesion fibers. The principal structural elements in lignin have been clarified largely as a result of detailed research based on modern analysis equipment and newly developed methods. Lignin is a kind of polycyclic macromolecular organic matter containing many negative charge groups. In the process of lignification of plant cell wall, the glycoside compound (coniferous glycoside) formed by coniferous alcohol and glucose is removed by enzymatic action, and the coniferous alcohol is deposited in cell wall and intercellular layer through polymerization to form lignin macromolecule. Alén proposed a large number of studies and showed that the content of functional groups in softwood lignin is different from that of hardwood lignin, and the phenolic hydroxyl, aliphatic hydroxyl, and carbonyl content of softwood lignin is higher than that of hardwood lignin, and the content of methoxy in hardwood lignin is higher (Alén, 2020). The world produces about 50 million T of annual industrial extraction of lignin (Gosselink et al., 2004), but only about $2 \%$ of lignin is commercially Industrial use, and the existing lignin-based products are mostly low-value-added products (e.g. dispersants, adhesives, water reducers, oilfield chemicals, etc.): the remaining large number of lignin is not separated directly discharged into rivers or concentrated directly after combustion to generate electricity, resulting in serious environmental pollution and significant waste of resources (Zhang, Wang, Zhang, Pan, \& Tao, 2016).

\section{References}

Ago, M., Huan, S., Borghei, M., Raula, J., Kauppinen, E. I., \& Rojas, O. J. (2016). High-throughput synthesis of lignin particles (approximately $30 \mathrm{~nm}$ to approximately $2 \mathrm{mum}$ ) via aerosol flow reactor: size fractionation and utilization in pickering emulsions. ACS Applied Materials \& Interfaces, 8(35), 23302-23310.

Alén, R. (2000). Structure and chemical composition of wood. Forest Products Chemistry, 3, 11-57.

Chinese Pharmacopoeia Commission Pharmacopoeia of the People's Republic of China. (2015). Beijing: China Medical Science Press.

Gosselink, R. J. A., Jong, E. D., Guran, B., \& Abächerli, A. (2004). Co-ordination network for lignin — standardisation, production and applications adapted to market requirements (EUROLIGNIN). Industrial Crops and Products, 20(2), 121-129.

Ralph, J., Lapierre, C., Marita, J. M., Kim, H., Lu, F., Hatfield, R. D., ... \& Van Doorsselaere, J. (2001). Elucidation of new structures in lignins of CAD-and COMT-deficient plants by NMR. Phytochemistry, 57(6), 993-1003.

Upton, B. M., \& Kasko, A. M. (2016). Strategies for the conversion of lignin to high-value polymeric materials: Review and perspective. Chemical Reviews, 116(4), 2275-2306.

Zhang, S., Wang, Z., Zhang, Y., Pan, H., \& Tao, L. (2016). Adsorption of methylene blue on organosolv lignin from rice straw. Procedia Environmental Sciences, 31, 3-11.

\section{Copyrights}

Copyright for this article is retained by the author(s), with first publication rights granted to the journal.

This is an open-access article distributed under the terms and conditions of the Creative Commons Attribution license (http://creativecommons.org/licenses/by/4.0/). 